\title{
Paradoxical respiration: 'Seesaw' motion with massive pulmonary consolidation
}

\author{
Takeshi Saraya, Masafumi Shimoda, Aya Hirata, Hajime Takizawa
}

Department of Respiratory Medicine, Kyorin University School of Medicine, Mitaka, Japan

\section{Correspondence to} Dr Takeshi Saraya, sara@yd5.so-net.ne.jp

Accepted 25 December 2015

\section{DESCRIPTION}

A 48-year-old woman was transferred to our hospital because of non-resolving pneumonia with rapidly progressive respiratory failure.

She had no remarkable medical history or history of illicit drug use. She was admitted to her local hospital 5 days before coming to our hospital with 4 days of fever and dry cough. With a tentative diagnosis of atypical pneumonia, she was treated with intravenous minomycin $(200 \mathrm{mg} /$ day $)$.

On admission (day 1), she was fully conscious and her vital signs were: temperature $37.2^{\circ} \mathrm{C}$; heart rate 85 bpm; blood pressure 104/70 mm Hg; $\mathrm{SpO}_{2} 90 \%$ on oxygen at $10 \mathrm{~L} / \mathrm{min}$ by mask (arterial blood gas (ABG): $\mathrm{pH} 7.453, \mathrm{pCO}_{2} 39.1$ Torr, $\mathrm{pO}_{2}$ 54.4 Torr, $\mathrm{HCO}_{3}^{-} 27 \mathrm{mmol} / \mathrm{L}$ ) and respiratory rate $36 \mathrm{bpm}$.

On physical examination, no adventitious breath sounds were noted, but the chest wall moved in during inhalation and out during exhalation together with dyssynchrony between the rib cage and abdomen (video 1), in a 'seesaw' type of motion, suggesting acute respiratory failure.

Chest X-ray (figure 1A) and thoracic CT (figure 1B) showed massive consolidation with air bronchogram and ground glass opacities in bilateral middle to lower lung lobes. Based on the radiological findings, the patient was diagnosed with acute interstitial pneumonia and was immediately treated with nasal high-flow oxygen therapy, intravenous steroid pulse therapy $(1000 \mathrm{mg} /$ day for 3 days/course for 3 courses) and an oral immunosuppressive drug (cyclosporine $150 \mathrm{mg} /$ day). Three weeks later, her seesaw motion disappeared with respiratory status improvement (SpO2 98\% on $3 \mathrm{~L} / \mathrm{min}$ oxygen via nasal cannula, $\mathrm{ABG}$ : $\mathrm{pH}$ 7.431, $\mathrm{pCO}_{2} 40.9$ Torr, $\mathrm{pO}_{2} 59.7$ Torr, $\mathrm{HCO}_{3}^{-}$ $26.7 \mathrm{mmol} / \mathrm{L}$ ). At that time, the lung lesions markedly improved as well (figure $1 \mathrm{C}, \mathrm{D}$ ).

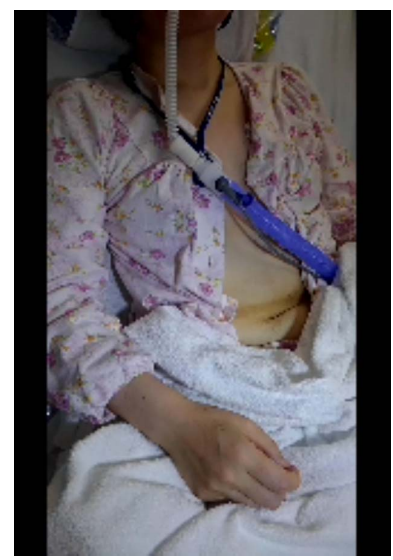

video 1 Seesaw motion on the day of admission

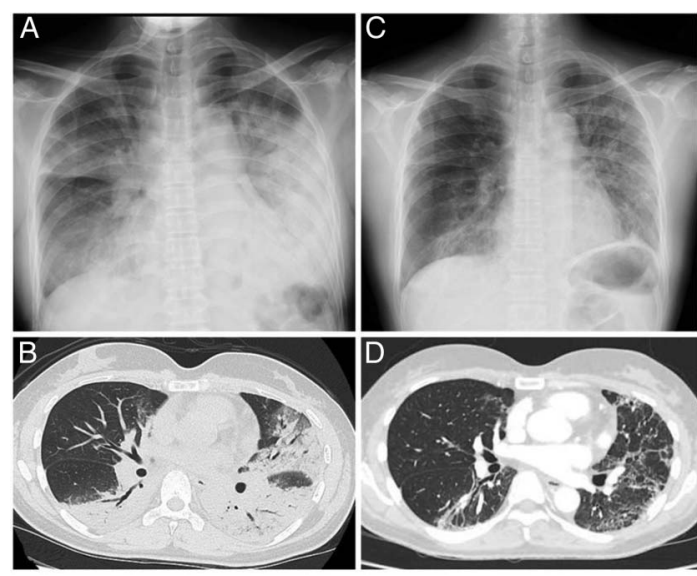

Figure 1 The pattern of respiration showing deflation of the lung during inspiration and inflation of the lung during expiration. Chest X-ray (A) and thoracic CT (B) on admission showed massive consolidation with air bronchogram and ground glass opacities in bilateral middle to lower lung fields. Three weeks later, those lesions almost disappeared except for faint ground glass opacities with mild consolidation and/or bronchiectasis (C and D).

Paradoxical respiration (seesaw motion) is a hallmark of inhibition of gas exchange due to diaphragmatic or respiratory muscle fatigue (ie, chronic obstructive lung disease) ${ }^{1}$ or traumatic injury to the thorax (flail chest), which may require urgent mechanical ventilation.

\section{Learning points}

- Seesaw motion is a type of paradoxical respiration, suggesting impaired gas exchange that might require mechanical ventilation.

- Seesaw motion suggests or predicts respiratory failure due to diaphragmatic or respiratory muscle fatigue.

Contributors TS, MS, AH and HT managed the patient. TS wrote the manuscript.

Competing interests None declared.

Patient consent Obtained.

Provenance and peer review Not commissioned; externally peer reviewed.

\section{REFERENCE}

1 Macklem PT. Respiratory muscle dysfunction. Hosp Pract (Off Ed) 1986;21:83-90. 5-6. 
Copyright 2016 BMJ Publishing Group. All rights reserved. For permission to reuse any of this content visit http://group.bmj.com/group/rights-licensing/permissions.

BMJ Case Report Fellows may re-use this article for personal use and teaching without any further permission.

Become a Fellow of BMJ Case Reports today and you can:

- Submit as many cases as you like

- Enjoy fast sympathetic peer review and rapid publication of accepted articles

- Access all the published articles

- Re-use any of the published material for personal use and teaching without further permission

For information on Institutional Fellowships contact consortiasales@bmjgroup.com

Visit casereports.bmj.com for more articles like this and to become a Fellow 